\title{
CONTINUOUS PROFESSIONAL DEVELOPMENT WORKSHOPS CAN BE AN OPPORTUNITY FOR CONSCIOUS AND INTENTIONAL KNOWLEDGE DEVELOPMENT: CASE-SPECIFIC REFLECTIONS
}

\section{Petro Botha}

\section{INTRODUCTION}

Social Work students who leave university to work within diverse institutional contexts often find it difficult to fit the "square pegs" of their contextual practice experience into the "round holes" of social work theory. This might lead to a feeling that theory is something done at university, with little application to the world of work, and that there is a divide between the world of formal theory development and the world of social work practice (Healy, 2005:xii).

The relationship between theory and practice has been extensively debated within the general field of learning (Dyke, 2009; Smith, 2007), within the field of social work (D'Cruz, Gillingham \& Melendez, 2007; Healy, 2005; Osmond, 2005; Osmond \& O'Connor, 2004; Sheppard, Newstead, Di Cacavvo \& Ryan, 2000), as well as in relation to post-compulsory education (Lynch, 2006; Parton, 2000). Most authors refer to the process as knowledge or theory development.

Healy (2005:97-102) identifies three forms of knowledge development: the evidence-based approach, reflective tradition and the reflexive approach. Evidence-based practice holds that social workers should use empirically tested methods of helping and should use scientific methods to test their own effectiveness. General principles are thus applied in theory and tested for their effectiveness (Sheppard et al., 2000:467). The social work researcher develops and tests the theory, which the practitioner then applies in practice. According to the reflective tradition, the practitioner's lived experience forms the basis of making and using knowledge in practice. The practitioner builds up exemplary themes through his or her case experience against which new variations in subsequent cases may be compared (Healy, 2005:100). Consistent with the reflexive approach, Healy (2005:100) recognises that social workers are always developing knowledge, not only through their experience, but also from sources, including their practice context and formal theory base.

Other authors use different distinctions to describe the methods of knowledge development. Sheppard (1998:765-767) distinguishes between "reflective practice", which emphasises a technical rationality through a focus on product knowledge, and "reflexive practice", which emphasises the importance of knowledge as a process. Instead of placing themselves outside of interaction to reflect upon it, practitioners recognises that they are involved in these interactions. D'Cruz et al. (2007:83-85) refer to three variations of "reflexivity", as well as to "critical reflection", "reflectivity" and "critical reflectivity". In "critical reflection", a critical incident in the past is used as a basis for knowledge generation and is considered as "reflectionon-action". The critical incident represents a learning opportunity for the future. According to D'Cruz et al. (2007:85), "reflectivity" refers to a process of reflection on knowledge building, while "critical reflectivity" means knowledge of the self in relation to social structures.

Various problem areas concerning the relationship between theory and practice during knowledge development have been identified. Osmond and O'Connor (2004:677-678) state that social workers in practice often do not use a formal, specific and specialised knowledge vocabulary to communicate their practice knowledge. Practice knowledge within specific organisational contexts is often not recognised or written into formal social work theory (Healy, 
2005:xiii). According to Proctor (2003:67-69), knowledge has traditionally been developed from "bench" to "trench", where "bench" refers to the academic setting and "trench" denotes practice or policy. More "bench-trench" partnerships need to be developed through methods such as focus groups, semi-structured interviews and "shadowing" of practitioners. Dyke (2009:295) refers to the need for an appropriate model of reflexive learning: "What is necessary is an approach that acknowledges that knowledge is created and recreated in a social context with others. This approach encourages people to critically engage with other forms of expertise, reflect upon the received wisdom of others, test it in practice and be open to the creation of knowledge that works in a given time and place".

Continuing professional development (CPD) affords professionals the opportunity to keep abreast of knowledge developments and advances in their field of work and holds the potential to bridge the divide between the world of knowledge development and the world of social work practice. Duffy (2003:35) argues that the staff developer is in a unique position to assist professionals to discover how their thinking influences their practice in unreflected ways, and to move beyond their fixed understanding of their work, which may have resulted in particular beliefs or assumptions. Through dialogue with a person situated in another context who has an interpretive understanding not familiar to practitioners, they can effectively explore their own practice, which will enable the unconscious to be made conscious (Lynch, 2006:84).

The SA Council for Social Service Professions (SACSSP) has formalised a statutorily determined CPD process that requires persons registered with the Council to attain a specified number of points annually to prove that they maintain quality service. Social workers can acquire these points by participating in professional activities registered with the Council. Such activities include workshops on analysing existing ideas, knowledge, skills and competencies and on addressing policy and practice (SACSSP).

CPD workshops create learning environments where "bench" and "trench" come together. The purpose of this article is to reflect on how CPD workshops within the field of social work can consciously and intentionally be utilised as an opportunity to develop the knowledge base of the field. A qualitative research approach was followed, using the six steps of the reflexive cycle in the heuristic research model as described by Poulter (2003:318-328), namely observing, describing, abstracting, generalising, assimilating and acting. The article focuses on the step of assimilation as a knowledge development framework; the Osmond's Knowledge Spectrum was linked to a workshop presented by the author to social workers from the Ekurhuleni Metropolitan Municipality, working in the field of physical and intellectual disability. Although the research is very limited, and refers only to the author's reflection on and analysis of data collected during one workshop, the purpose of the article would be met if it could open up this topic for discussion amongst workshop presenters and participants within the field of social work.

\section{RESEARCH METHODOLOGY}

The various ways of knowledge building, including reflexive and reflective practice described in the introduction, have not readily been accepted as "real" forms of research, but as heuristic case practice (Poulter, 2003:318). By developing a heuristic research model, based on the previous work of Lang, Poulter relates reflexive and reflective modes of case practice to accepted methods of exploratory types of qualitative research. "Reflexive case practice" can be described as interventive research which is aimed at developing a "theory of one" to understand the complexity of individual client circumstances in order to formulate appropriate individual 
interventions. "Reflective case practice" refers to modelling research which aims at linking findings from several cases in interventive research. The heuristic research model shows the relationship between reflexive and reflective practice and aims, firstly, at developing a casespecific theory that will guide practice and, secondly, to build new knowledge by postulating relationships between insights gained in the class of related cases. This model can be used by both the academic researcher and the practitioner (Poulter, 2003:318-319,321).

FIGURE 1

\section{HEURISTIC RESEARCH MODEL}

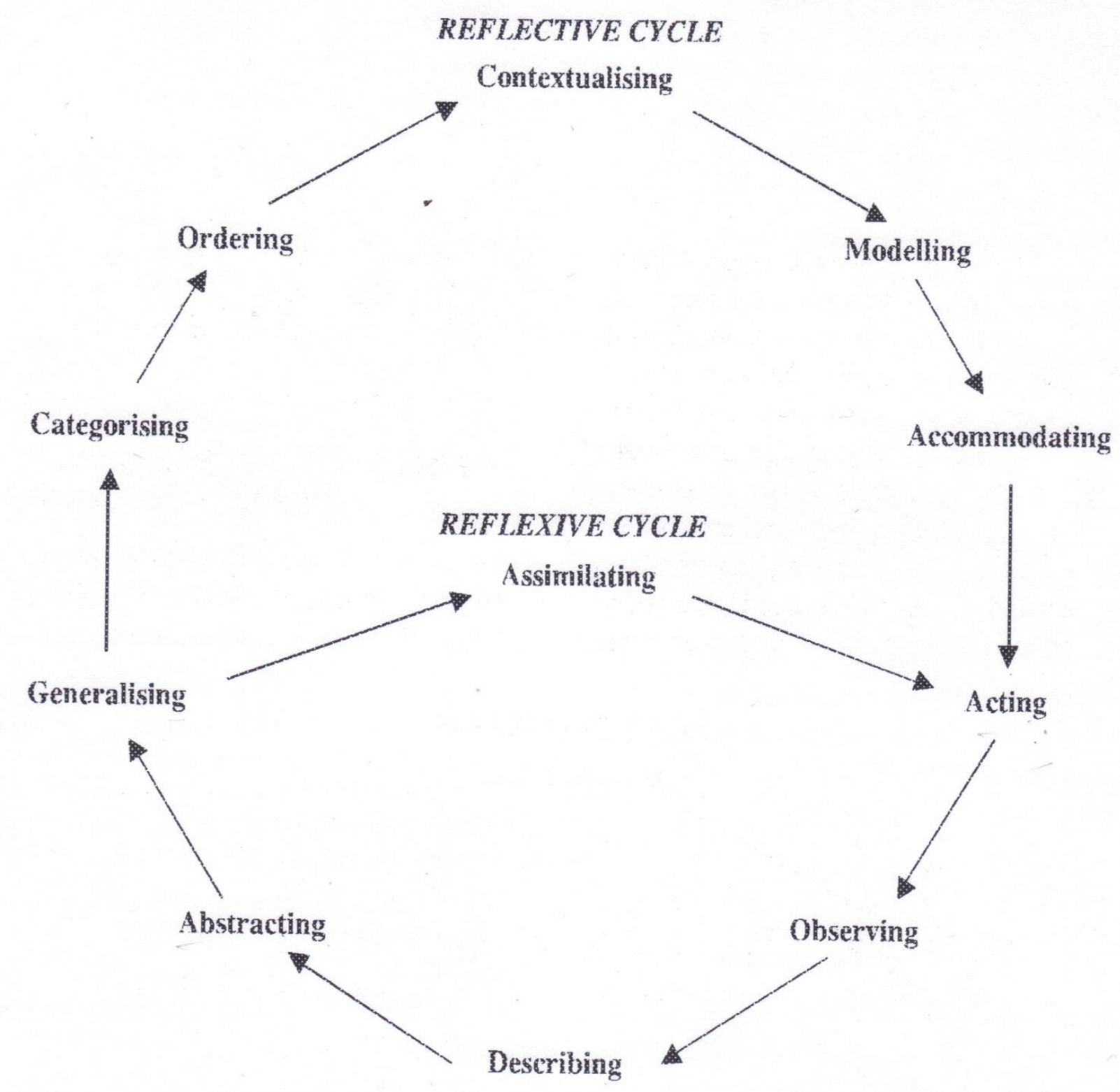

The heuristic research model of consists of the "reflective cycle" and the "reflexive cycle". As indicated by Figure 1, the reflexive cycle is subsumed within the reflective cycle. The shorter reflexive cycle corresponds with the interventive research process, while the longer reflective loop corresponds with the modelling research process. The full cycle consists of 11 steps namely observing, describing, abstracting, generalising, assimilating, categorising, ordering, 
contextualising, modelling, accommodating and acting. For the purposes of this article, I will focus only on the reflexive cycle, as I am reflecting on one workshop.

\section{Application of the heuristic research model in reflecting on a workshop with social workers from the Ekurhuleni Metropolitan Municipality}

\section{BACKGROUND}

Early in 2011 the University of South Africa (Unisa) was approached by the Ekurhuleni Metropolitan Municipality to develop a series of CPD workshops for a group of social workers employed by the municipality at local government level. One of the themes to be covered was disability care management. Since I had worked in the field of disability for many years, I was approached to develop a two-day workshop on disability care management to ten social workers. As I was not familiar with social work within the context of local government, I did not understand the role of the social worker working with people with a disability at this level and how this was influenced by the organisation's policies and goals. I e-mailed the training coordinator for clarity on the way that disability care management, which can be defined as "an approach designed to identify a strategy for managing and coordinating services to a particular service-user", would apply to social work within the context of a metropolitan municipality (Leyshon, Clark, Epstein \& Higgins, 2004:845). Because of my lack of knowledge of the work context, I expected that the theory on disability care management, which I had included in my workshop presentation, might need to be adjusted by the participants' practical knowledge to be meaningful to them.

After consultation, I planned the workshop programme, which included discussions on the definition and fields of disability and the government's approach to disability. I also planned to link this with the participants' personal approach to disability. During the workshop the field of disability within the local government would be mapped and a SWOT analysis done of the local government, with reference specifically to its work with people who have a disability. The concept "disability care management" would be defined, and the roles and skills of the care manager described. I planned that the current use of disability care management would be discussed in the group and that the participants would be requested to develop their own theoretical framework for disability care management. Through this activity, I wanted to create an opportunity for practical knowledge to be recognised and the knowledge I presented to be adjusted, or for new knowledge to be developed. As part of my planning, the participants would be asked to identify their own strengths and opportunities for growth as well as areas for future research during the second day of the workshop. The participants gave their consent that the information generated during the workshop could be used as part of this research. Consent was confirmed when the author interviewed the supervisor of the participants, who also participated in the workshop, a few weeks later. The six steps of the reflexive cycle in the heuristic research model and its application to the reflection on the workshop are described in the next section.

\section{STEP 1: OBSERVING}

The research process starts with observation. At this stage one attends to the peculiarities of the situation at hand without trying to link what is observed to an overarching theory (Poulter, 2003:321). The author observed the process of interaction between the presenter and the participants and the role of theory and practice during the workshop. 


\section{STEP 2: DESCRIBING}

Data are gathered to provide rich sources which could be used later to decide what the observed and described data mean. A researcher will gather process recordings and a practitioner case notes (Poulter, 2003:321-322). During the workshop the author made notes of her observations, asked the participants to write down information generated during activities and discussions on big sheets of paper, which were kept for later analysis. The author also requested participants to complete a questionnaire to evaluate the workshop, and interviewed the supervisor of the social workers, who also attended the workshop on clarifying some practical details of case studies referred to during the workshop. During this interview we also reflected on the role of theory and practice within the context of the world of work.

\section{STEP 3: ABSTRACTING}

As part of conceptualisation the data gathered are freed from time and place by abstraction. For the practitioner this will take the form of assessment, looking at roles, relationships and potential meaning (Poulter, 2003:322). The author identified the roles of the workshop presenter and the participants as well as expectations and behaviours as far as the use and development of theory and practice were concerned. It seemed from the author's perspective that the participants expected the presenter to bring the "right" theory which should fully fit their practice situation. It also seemed that the participants were not keen to develop new knowledge by creating a framework of disability care management which would fit their situation.

\section{STEP 4: GENERALISING}

Clusters of abstractions or innate patterns are observed as vehicles for new insights (Poulter, 2003:322). During the workshop different case studies from practice were used to compare theory and practice - to see which descriptions of disability case management would fit where. It seemed that the participants felt comfortable about applying the theory to practice within their context, but not to change existing theory or to develop a new framework. Practice was documented, however, which participants appreciated.

\section{STEP 5: ASSIMILATION}

During this stage data are linked to existing theory. Practitioner will use the new information to respond to the situation at hand. If practitioners move to the reflective cycle, they will start developing new knowledge and evolve their own classifications and conceptualisations (Poulter, 2003:322-323). The author did a literature review on different frameworks which describe the relationship between theory and practice, including a framework for reflexive learning by Dyke (2009), the dynamic model for social work practice by Healy (2005) and the knowledge spectrum framework developed by Osmond (2005). She decided to link the data on the workshop to the knowledge spectrum framework, as it focuses specifically on the field of social work and not only depicts different types of knowledge and the interactions between them, but also presents different options on how knowledge can be received. This framework can also be utilised as a tool to show that knowledge can be created, modified and discarded by practitioners (Osmond, 2005:881). The framework could thus give meaning to the data gathered. A detailed description will be given of this step of the research process in the next section, as it forms the core of the reflection.

\section{STEP 6: ACTION}

Researchers often stop before this step, being content with knowing. For the practitioner, the last step refers to the operationalising of the new knowledge. Knowledge gained from practice 
is tested in practice. Unresolved issues can lead to the practitioner going back to the reflexive cycle or move into the bigger reflective cycle, which will more likely lead to the development of new knowledge for the profession (Poulter, 2003:325,327). The author moved out of the cycle before the action step, but plans to test the tool during future workshops. She also invites other researchers to think about the topic and even use Osmond's framework in practice. This might lead us into the reflective cycle.

\section{OSMOND'S KNOWLEDGE SPECTRUM}

Osmond (2005:881-900) has developed a framework to illustrate that knowledge use in practice is a dynamic and evolving process. The framework assists students in clarifying and developing their own practice frameworks, to recognise their knowledge imbalances or gaps, and to see the importance of tacit or unconscious knowing. Figure 2 depicts Osmond's knowledge spectrum framework, showing the dynamic relationship between different knowledges that can inform social work practice as well as their interconnections.

\section{FIGURE 2}

OSMOND'S KNOWLEDGE SPECTRUM FRAMEWORK (OSMOND 2005: 884)

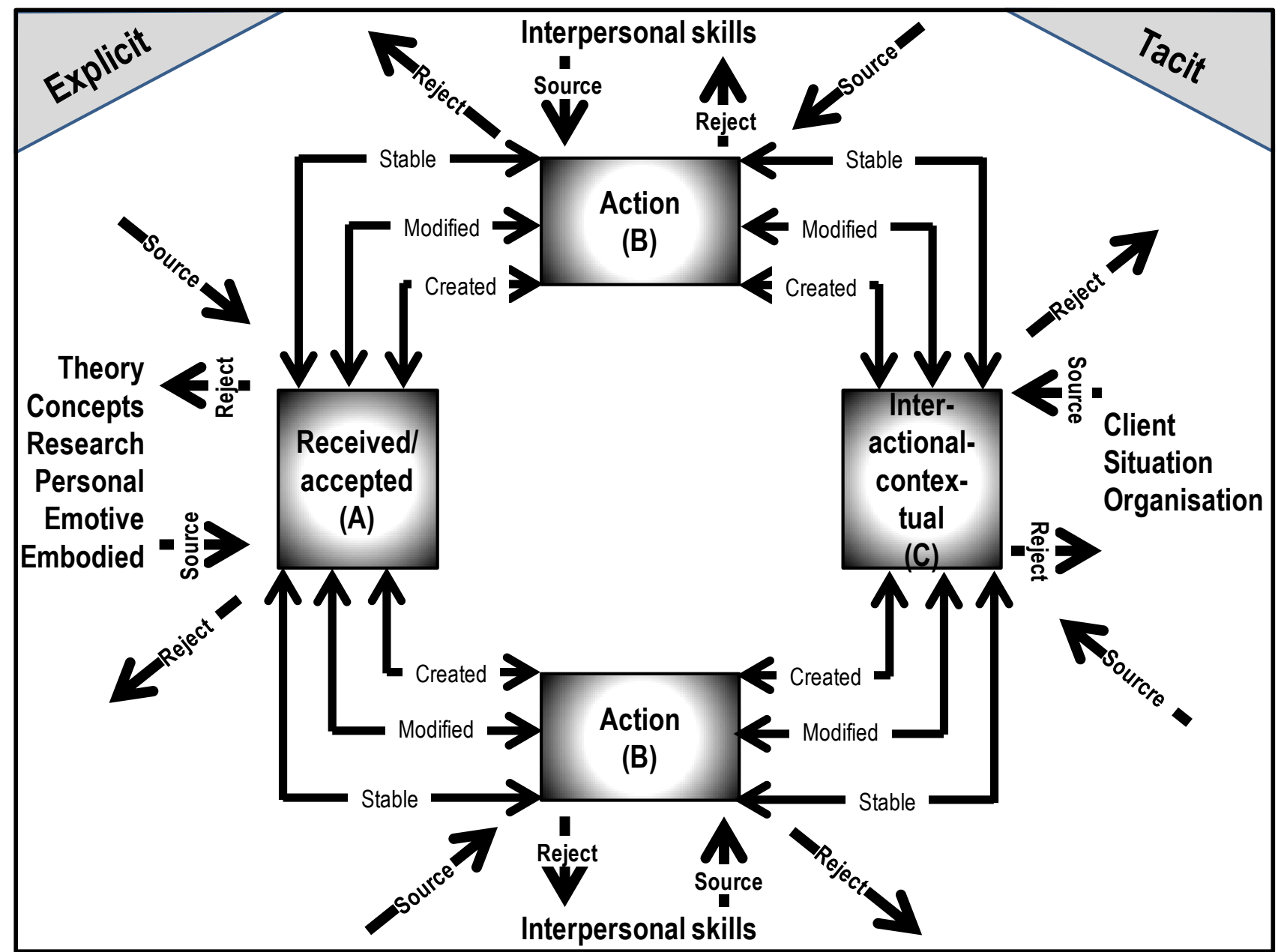

Osmond (2005:885) identifies three knowledge categories (represented by the square blocks marked A, B and C in Figure 2), four knowledge opportunity arcs (depicted by the arrows) and six sources of knowledge (listed next to block A). The framework also stresses that practice can be informed by explicit (consciously aware) and tacit (implied, unconscious) knowledge (the sides of the cube). There is a dynamic interaction between these components, and the 
framework has a number of knowledge entry and exit points. The framework can progress clockwise or anti-clockwise: one can enter interpretation at any point and move in any direction. You can, for instance, start with a specific theory and investigate how it is applied in practice within a specific context. You can also identify a specific skill and investigate its relationship with theory and applicability within a specific interactional context.

The framework comprises three major interconnected knowledge categories:

- received or accepted knowledge, which refers to constructed knowledge or knowledge in the process of construction, as well as to any of the six types or sources of knowledge described below;

- action, representing performance or technical knowledge - the know-how of practice;

- interactional-contextual knowledge, which emphasises the impact of the previous categories of knowledge on the client, situation or organisation; additionally, it represents knowledge that arises in situations, contexts and with clients.

Six types of accepted or received knowledge are identified:

- theory can be formal or informal and refers to the methods of social work or explanations of clients' behaviour;

- concepts: theory assumes a connection between a number of concepts, propositions or ideas;

- research refers to outcomes or findings of social research or knowledge of the research process;

- personalised knowledge refers to practice wisdom (whether articulated or not) and personal as well as professional values and beliefs;

- emotive knowledge refers to feelings which assist in assessing people or situations;

- embodied knowledge refers to knowledge conveyed to others by our bodies; that is, body shape, facial expression and movement.

Within each knowledge category there are four knowledge-opportunity arcs, or options of how knowledge can be received:

- rejected/discarded: if we hear or see something that we do not agree with, we do not integrate it into our existing understanding of the world;

- stable and unchanged: knowledge can be uncritically accepted as is and used;

- modified: knowledge can be crafted according to a specific situation, circumstances, place and time; knowledge can be personalised;

- created: knowledge can stimulate the creation of new schemas or ways of understanding.

All the aforementioned knowledge categories, sources and processes can impact on and direct practice behaviour on an explicit and/or tacit level. The student knows on an explicit level when he/she is consciously considering knowledge, or knows on a tacit level when knowledge is not consciously attended to (Osmond, 2005:897).

Osmond (2005:882) suggests that this framework can be taught to students in four stages:

- orientating: students can be asked to consider what social work knowledge is; the significance of clear knowledge-guided practice can be addressed; 
- explaining the whole and the connections between the knowledge types - the spectrum framework and its parts can be explained;

- explaining content: the different knowledge types contained in the three main categories can be critically discussed;

- recognising the complexity: students are made aware that practice is informed by both explicit and tacit knowledge.

\section{ASSIMILATING OSMOND'S KNOWLEDGE SPECTRUM WITH THE WORKSHOP EXPERIENCE}

The author will refer to a few items on the workshop programme to illustrate the assimilation of Osmond's theory with data gathered.

\section{DEFINITIONS OF, AND APPROACHES TO, DISABILITY}

During the first part of the programme the participants compared their understanding of disability with definitions from theory - personalised knowledge and interactional-contextual knowledge were compared with received knowledge. We discovered that, in contrast to the theory, the Ekurhuleni Metropolitan Municipality does not define mental illness as a disability. This led to a discussion about the effect that institutional policy and context have on the rights of persons with mental illness.

In order to better understand the experience of a person with a disability, participants shared with one another how their functional limitations affect their everyday life. One participant, for example, was losing her memory, while another had difficulty walking after breaking an ankle. This activity added to the participants' emotional knowledge. In one of the activities the participants were asked to reflect on their own beliefs about people with disabilities and how this influenced their approach to their work (personalised knowledge). We then discussed the government's approach to disability (disability is not seen as a feature of the individual, but as the limitations the physical and social environments imposed on a client). It seemed that some participants do experience a discrepancy between the accepted knowledge (the approach followed by the government) and their own beliefs, e.g. that disability is a feature or problem of the client and that the practitioner has to fix the problem (personalised knowledge).

\section{THE ROLE AND CONTEXT OF SOCIAL WORK WITHIN THE EKURHULENI METROPOLITAN MUNICIPALITY}

In a group activity the participants mapped the field of disability and specifically the larger structure of the Ekurhuleni Metropolitan Municipality (EMM) with all the relevant role-players at a departmental and interdepartmental level. This clarified and confirmed the interactionalcontextual knowledge for the participants and the workshop presenter. Participants identified their own role or goals as shaped by the interaction between the context of local government and the accepted knowledge of methods within social work and the field of disability. Within the Ekurhuleni Metropolitan Municipality their role is to:

- facilitate or promote development programmes, for example, learnerships or skillsdevelopment programmes for people with a disability;

- monitor and evaluate these programmes;

- coordinate services in and support existing NGOs and CBOs for people with a disability;

- promote an integrated approach by working with other local government departments, for example, the Department of Sport and Recreation or the Department of Housing; 
- lobby and advocate for people with a disability (this includes awareness campaigns);

- link NGOs and CBOs with relevant resources.

The next step in the workshop programme was to discuss how the theory on disability care management could inform the role or goals set for social workers within local government.

\section{DISABILITY CARE MANAGEMENT}

I shared a definition of care management as well as two frameworks of disability care management with the participants. I also discussed the literature on multi-professional communication which I had found and which I thought would specifically assist the social workers at a local government level (received knowledge: theory). I asked the participants to compare their action knowledge on disability care management in groups and to develop their own framework for disability care management as applicable to their context. I thus requested the participants to modify the theory to suit their institutional context or create new theory. The participants became very uncomfortable and explained that their understanding of care management was different and that they had expected theory on the characteristics and experiences of people with a disability (I observed their discomfort in their body language embodied knowledge). Participants decided not to do the homework, but to do the activity as a group the next day. It seemed that the participants wanted to apply theory unchanged and that they did not feel comfortable with other knowledge opportunity arcs. It seemed that they had not yet recognised the potential of the dialogue between workshop participants and the presenter. This, however, was only my observation on a tacit level.

The next morning we reflected on the process of the workshop and what was happening. We thus engaged in a reflexive learning process on an explicit level - not only focusing on what we were busy with, but on both the participants' and presenter's roles in knowledge development. I tried to make them aware of the flexible nature of knowledge (four knowledge opportunity arcs) and the vast amount of practical or action knowledge which they had accumulated by working within the field of disability. To address the need expressed the previous day, I presented theory on the categories of human experience and asked the participants to add the specific experiences of people with a disability using their action knowledge. This worked well and the author's observation was that the participants started to trust their own knowledge; they also started to see theory as not necessarily stable, but as something which could also be modified or created.

\section{EXPERIMENTING WITH DISABILITY CARE MANAGEMENT}

In the next part of the workshop we placed theory next to practice, taking the unique context of the municipality into account. In order to clarify our reflexive process, I will summarise one of the theoretical frameworks on disability care management as well as its practical application.

One of the roles or goals of social workers within the Ekurhuleni Metropolitan Municipality is to facilitate or promote the development of people with a disability by facilitating learnerships, skills-development programmes and employment opportunities for people with a disability. At a local government level this is done by forming partnerships and liaising with other roleplayers, for example the Sector for Education and Training Authorities (SETAs), NGOs and businesses. One of the businesses that is doing much for people with a disability as part of their employment equity policy is Emperor's Palace. The participants placed the theory, in this case the process of disability care management as described by O'Connor, Hughes, Turney, Wilson and Setterlund (2006:160) next to their role of care management at a local level. The process of disability care management follows seven basic steps which are linked to the case practice. 
1. Publishing information: The disability care manager makes the public aware of the needs for which assistance is offered and the resources for meeting those needs. The social workers from the municipality inform the disability forums as well as the NGOs and CBOs when Emperor's Palace is offering training or employment to people with a disability.

2. Determining the level of assessment: An initial identification of needs is made and the appropriate level of assessment of that need is determined. Emperor's Palace has set specific criteria for training or employment; for example, people with a disability need to have a Grade 12 qualification, must have transport, and need to cope with the demands of the workplace.

3. Assessing need: The disability care manager needs to understand individual needs, relate them to the agency's policies and priorities, and set objectives for any intervention. While comparing Emperor's Palace's criteria with the needs and abilities of the clients, the participants identified obstacles for people with a disability. Often people with a disability (especially people with a learning disability) do not reach a Grade 12 level. They often experience difficulty with transport and do not cope with the requirements of the workplace, for example, long hours. They sometimes lack the social skills expected by the employer.

4. Care planning: The most appropriate ways of achieving the objectives must be identified by the assessment of needs and incorporating them into an individual care plan. Within the context of the municipality, the care plan will not focus on individual needs, but on how best the social workers at local government level can utilise resources to fulfil the needs of all the people with a disability in their regions. The participants realised that they needed to focus more on advocacy to challenge the educational criteria set for clients. Other obstacles lie on the level of NGOs and CBOs, namely transport, life skills and job coaching. We discussed the importance of job coaching, but it was felt that roles in this regard needed to be clarified - who would be responsible for job coaching: Emperor's Palace or the grassroots organisations?

5. Implementing the care plan: The necessary resources and services must be secured. The participants planned to go back and implement the care plan. They could, for example, discuss this at the EMM or regional forum level and had to decide how they would address the issues of admission criteria at a policy level.

6. Monitoring: The disability care manager supports and controls the delivery of the care plan on a continuing basis. Implementation of the municipal social workers' plan needs to be monitored on a continuing basis.

7. Reviewing: Needs and service outcomes are reassessed with a view to revising the plan at specific intervals. The participation of people with a disability in the Emperor's Palace's programme needs to be reviewed on a regular basis to see whether identified obstacles have been adequately addressed. If not, the social workers need to return to point 4.

The dialogue between the presenter, coming from the outside with a different interpretive understanding, and the participants assisted them to look beyond their fixed understanding of the situation of their clients and their roles, and made them aware of different ways to approach their work. They clearly identified obstacles preventing clients from fully utilising the resource, Emperor's Palace. They also realised that the roles of the different role-players, Emperor's Palace and the NGOs, concerning who needs to provide job coaching were not clear. They understood that, as social workers at a local level, they needed to focus more on advocacy and 
trying to change the admission criteria for employment as set, not only by Emperor's Palace, but also by other potential employers of people with a disability. Placing the theory (accepted knowledge), usually applied in a one-to-one situation, and not a local government context, next to their practice enriched the social workers' perspective on their clients' situation and the possible ways in which they could deal with it. The social workers were not ready, however, to develop their own framework for disability care management which would be more applicable to the local government context.

\section{MAINSTREAMING DISABILITY}

For the rest of the workshop we discussed the skills needed for disability care management, but the participants requested that we focus on the mainstreaming of disability (the integration of the needs of people with a disability within all policies), an aspect which I had just touched on in my preparation. I thus facilitated a discussion where the participants could use practice or action knowledge as well as interactional contextual knowledge. The participants realised that they had already done much to mainstream disability, for example, by means of their awareness campaigns, learnership programmes and work-skills development. They wanted to focus more on:

- following up the decisions they had taken with their own department, the Mayor's office;

- the DPSA and the national councils;

- building and maintaining relationships with the above organisations;

- intensifying their role of advocacy and lobbying through the Ekurhuleni Metropolitan Municipality Marketing Department.

The group then realised that they needed to be more specific in their planning and that they needed to allocate responsibilities to specific people who had to be accountable for a specific tasks as well as specific deadlines. Participants used the theory discussions to set clearer action or practice goals for themselves within their specific context - in this case, the local government.

\section{DISCUSSION}

In order to make sense of the workshop as a critical incident of learning I will first reflect on the feedback given on the workshop by the participants, the feedback from the supervisor during our interview and my own evaluation notes. The reader should keep in mind that the discussion is based only on observations. I will then reflect on what I have learned from using the heuristic research model and specifically from the assimilation step.

At the end of the two-day workshop we evaluated the workshop as a group. I specifically asked the participants whether they would still prefer a person from outside their context to present workshops, or whether it would not be better if a colleague facilitated them. I also asked the participants to complete a questionnaire asking feedback on the content, facilitation and usefulness of the workshop.

From the above it seemed that:

- all the participants still preferred an outsider to do the workshop as this provides the necessary distance to reflect meaningfully on what they do;

- nine participants out of the ten found the models of disability care management most useful; 
- $\quad$ all ten participants would recommend the workshop to their colleagues and stated: "It help us to structure our work properly."; "I think there is a lot to learn from this training, even if you already do some work, it assist you to follow up and do assessment."; "It will assist to link theory/models with what we are doing currently" and "to assist with different target groups, for example women, men youth and kids";

- one participant said that the facilitator was able "to think theory into practice";

- two participants suggested that the presenter should get to know the context better before presenting a workshop;

- During our interview the supervisor stated that theory is important for practice as it gives direction to practice, enables one to think outside the box, gives alternatives and "flags" things for you, and it provides guidance when there is conflict. She was of the opinion that theory "doesn't work" when one insists that the social worker should focus on theory which does not allow for flexibility. The supervisor felt that knowledge at university level does not prepare social workers for practice. Unfortunately, we did not focus on the conscious and purposive development of knowledge within a workshop context.

In my evaluation notes, I wrote:

- Social workers in the field still seem to feel that formal theory should be applied unchanged in practice;

- They underestimate the value of their day-to-day practice knowledge;

- Social workers as practitioners do not feel they have the authority to modify theory or to create their own theory;

- The expectation is thus that a presenter of CPD workshops should be an expert who delivers the "correct" theory to apply in practice.

The participants preferred an outsider to do the training, which corresponds with the view of Duffy (2003:35) and Lynch (2006:84) that, through dialogue with a person situated in another context who has an interpretive understanding not familiar to practitioners, the practitioners can effectively explore their own practice and beliefs and move beyond their fixed understanding of their work. Reflections also correspond with Osmond and O'Connor's (2004:677-678) statement that social workers in practice often do not use formal, specific and specialised knowledge vocabulary to communicate their practice knowledge. From their feedback it did seem, however, as suggested by Dyke (2009:295), that participants were not yet open to an approach that acknowledges that knowledge is created and recreated in a social context with others.

From the application of the heuristic research model, and specifically by assimilating Osmond's knowledge spectrum with the workshop experience, I gained a new and specific understanding of the dynamic process of knowledge creation - types of knowledge, interaction between types of knowledge and how knowledge can be received. This framework can also be utilised as a tool to show that knowledge can be created, modified and discarded by practitioners and can be taught to students or practitioners as a tool (Osmond, 2005:881). It can thus empower practitioners to actively participate in the process of knowledge development and not only passively receive knowledge. The knowledge spectrum can provide practitioners with a "language" to articulate and share their practice experience. The steps suggested by Osmond (2005:882-883) to teach the framework to students can also be used during workshops. Participants can be orientated to consider what social work knowledge is, and the significance 
of clear knowledge-guided practice can be addressed. The workshop presenter can explain the spectrum framework and its parts. The different knowledge types contained in the three main categories can be discussed critically and participants can be made aware that practice is formed by explicit and tacit knowledge. In this way workshop participants can became aware of their role in knowledge creation and can consciously and intentionally participate in the dialogue between theory and practice. Since social workers can earn points for attending accredited CPD workshops, workshops are in demand and can - in comparison to other methods mentioned by Proctor (2003:68), e.g. focus groups, semi-structured interviews or "shadowing" - be an accessible and cost-effective way to form "bench" to "trench" partnerships.

\section{CONCLUSION}

Social work students who leave university to work within diverse institutional contexts often find it difficult to fit the "square pegs" of their contextual practice experience into the "round holes" of social work theory (Healy, 2005:xii). Continuing professional development (CPD) bridges the apparent divide between theory and practice. CPD workshops create learning environments where "bench" and "trench" come together. The purpose of this article was to reflect on how CPD workshops in the field of social work can consciously and intentionally be utilised as an opportunity to develop the knowledge base of the field.

The author reflected on one workshop she presented to social workers from the Ekurhuleni Metropolitan Municipality, working in the field of physical and intellectual disability, using the heuristic research model. From her reflections it seems that workshops, and specifically CPD workshops, can be more than places where knowledge is given and received. They can be reflexive learning environments where practice knowledge is acknowledged and written up, and where discussion with a person outside the practical context can create new insights. They can be environments in which practitioners are empowered to create, modify or discard knowledge. The author is of the opinion that this can be achieved by teaching Osmond's knowledge spectrum to practitioners attending CPD workshops. This framework provides a tool to create awareness of the process of knowledge development and provide the language to enable participants to engage actively in this process. It thus seems CPD workshops in the field of social work can consciously and intentionally be utilised as an opportunity to develop the knowledge base of the field.

Although her reflection is extremely limited and can thus not be generalised to other workshop experiences, the author would hope to generate discussion between workshop presenters and practitioners in the field of social work. It would be helpful if other workshop presenters in the field of social work similarly reported on their experience of knowledge development through reflexive learning. The present research could be taken a step further by intentionally teaching Osmond's knowledge spectrum to workshop participants and recording the outcomes as far as the dynamic relationship between theory and practice is concerned. It might be found that the "oval" peg of practice knowledge does fit into the "oval" hole of unchanged, modified or newly created knowledge. 


\section{REFERENCES}

ANFARA, V.A. 2008. Theoretical frameworks. The Sage Encyclopaedia of qualitative research methods. [Online] Available: http://www.sagereference.com/view/ research/n453.xml. [Accessed: 21/09/2011].

D'CRUZ, H., GILLINGHAM, P. \& MELENDEZ, S. 2007. Reflexivity, its meaning and relevance for social work: a critical review if the literature. British Journal of Social Work, 37:73-90.

DUFFY, F.M. 2003. I think, therefore I am resistant to change: what we know - or think we know - is our biggest roadblock to learning. National Staff Development Council, 24(1):3136.

DYKE, M. 2009. An enabling framework for reflexive learning: experiential learning and reflexivity in contemporary modernity. International Journal of Education, 28(3):289-310.

HEALY, K. 2005. Social work theories in context. Creating frameworks for practice. New York: Palgrave MacMillan.

LEYSHON, S., CLARK, L.L., EPSTEIN, L. \& HIGGINS, S. 2004. Caring for people with learning disability using care management. British Journal of Nursing, 13(14):845-847.

LYNCH, A. 2006. The place of structural self-reflexivity in our ongoing educational journey as social workers. Social Work Review, Summer:78-89.

O’CONNOR, I., HUGHES, M., TURNEY, D., WILSON, J. \& SETTERLUND, D. 2006. Social work and social care practice. London: Sage Publications.

OSMOND, J. 2005. The knowledge spectrum: a framework for teaching knowledge and its use in social work practice. British Journal of Social Work, 35:881-900.

OSMOND, J. \& O'CONNOR, I. 2004. Formalizing the unformalized: practitioner's communication of knowledge in practice. British Journal of Social Work, 3:677-692.

PARTON, N. 2000. Some thoughts on the relationship between theory and practice in and for social work. British Journal of Social Work, 30:449-463.

POULTER, J. 2003. Research and theory building functions of heuristic case practice. Australian Social Work, 56(4):318-328.

PROCTOR, E.K. 2003. Developing knowledge for practice: working through "trench-bench" partnerships. Social Work Research, 27(2):67-69.

SHEPPARD, M. 1995. Social work, social science and practice wisdom. British Journal of Social Work, 25:265-293.

SHEPPARD, M. 1998. Practice validity, reflexivity and knowledge for social work. British Journal of Social Work, 28:763-781.

SHEPPARD, M.S., NEWSTEAD, S., D.I. CACAVO, A. \& RYAN, S. 2000. Reflectivity and the development of process knowledge in social work: a classification and empirical study. British Journal of Social Work, 30:465-488.

SMITH, S.R. (ed) 2007. Applying theory to policy and practice. Hampshire: Ashgate. 
SOUTH AFRICAN COUNCIL FOR SOCIAL SERVICE PROFESSIONS. (n.d.) Policy on continuing professional development (CPD) for persons registered with the South African Council for Social Service Professions. [Online] Available: http:/www.sacssp.co.za/ index. php.page ID=32\&pagename=/EDUCATION,-TRAINING-, \& DEV/ [Accessed: 22/09/2011].

I would like to acknowledge the contributions of the social workers of the Ekurhuleni Metropolitan Municipality who participated in the workshop, as well as those of Ms Beauty Nthite, their supervisor, with whom I conducted an interview.

Ms Petro Botha, Department of Social Work, University of South Africa, Pretoria, South Africa. 